\title{
LA EXTRAORDINARIA Y URGENTE NECESIDAD EN EL REAL DECRETO-LEY 5/1996, DE 7 DE JUNIO, DE MEDIDAS LIBERALIZADORAS EN MATERIA DE SUELO Y DE COLEGIOS PROFESIONALES
}

\author{
José Luis Avila Orive \\ Profesor Titular de Derecho Administrativo de la Universidad de Deusto
}

Sumario: I. Introducción. II. El presupuesto habilitante: la extraordinaria y urgente necesidad. II.1. Lo necesario. II.2. Lo extraordinario. II.3. Lo urgente. II.4. El examen del Real Decreto-Ley 5/1996, de 7 de junio, de medidas liberalizadoras en materia de suelo. II.5. Los efectos de la nulidad del cuestionado Decreto-Ley. II.6. Los límites materiales.

\section{Introducción}

Ciertamente, la promulgación de este Real Decreto-Ley ha supuesto una notable sorpresa y desconcierto en el mundo urbanístico. No por la pretensión reformadora del nuevo Gobierno, cuyas discrepancias con el ordenamiento urbanístico vigente eran conocidas, sino por el instrumento utilizado, la pretendida urgencia de que se le acompaña y el ámbito y extensión de la propia reforma. A la situación de incertidumbre existente, debida a las impugnaciones contra la Ley 8/1990 y el Decreto Legislativo 1/1992, ahora se le añade la que representa la citada norma jurídica con fuerza de Ley.

Los efectos que este Real Decreto-Ley produce pueden sistematizarse en torno a cuatro grandes apartados, como son la terminación de la distinción entre suelo urbanizable programado y no programado, la modificación del régimen de aprovechamiento y cesión de suelo a los Ayuntamientos, la reducción de los plazos de tramitación del planeamiento y la modificación de la Ley 7/1985 de Bases de Régimen Local. En cualquier caso antes de abordar estos efectos, resulta conveniente realizar un análisis del grado de cumplimiento de los parámetros constitucionales por parte del Real Decreto-Ley. 


\section{El presupuesto habilitante: la extraordinaria y urgente necesidad}

La fórmula contenida en el artículo 86.1 de la Constitución ha sido objeto de análisis y pronunciamientos por parte del Tribunal Constitucional, y de estudio doctrinal, de tal modo que hoy están básicamente delimitados los contornos de esas disposiciones legislativas provisionales que toman forma de Decretos Leyes. Es necesario llevar a cabo un ejercicio de contraste con esos límites a fin de comprobar su respeto o vulneración por el Decreto-Ley de medidas liberalizadoras en materia de suelo y colegios profesionales.

\section{II.1. Lo necesario}

El citado artículo 86.1, como es sabido, establece: «En caso de extraordinaria y urgente necesidad, el Gobierno podrá dictar disposiciones legislativas provisionales que tomarán la forma de Decretos-Leyes...». Realmente en la transcrita cláusula se aprecia el carácter excepcional de tal vía de producción de normas jurídicas con fuerza de Ley, al margen del procedimiento legislativo ordinario. Sin embargo, la excepcionalidad, como se podrá comprobar, no se deduce de la mayor o menor versatilidad de dicha norma para poder ser utilizada por el Gobierno, en función del cumplimiento de los requisitos impuestos ex Constitutione, sino de la posibilidad de crear normas jurídicas con valor de Ley, al margen del procedimiento legislativo ordinario, siempre que se cumplan los límites o requisitos que la Constitución establece ${ }^{1}$. Dicho con otras palabras su carácter excepcional no obedece a que sea utilizado en raras ocasiones, aunque es verdad que si esto fuese así se fortalecería el entendimiento de la excepcionalidad, sino a que su utilización se aparta de la regla general, que es el procedimiento legislativo ordinario. Como más adelante se verá, el carácter de la necesidad habilitante implica la consideración del Decreto-Ley por el Tribunal Constitucional, como un instrumento normativo no totalmente excepcional, pero caracterizado, sin duda, por este elemento.

Alguna doctrina ha apreciado una cierta evolución en la jurisprudencia constitucional, respecto a la valoración de la necesidad habilitante para poder dictar un Decreto-Ley, fijándose en reflexiones que el Tribunal realizaba en torno a la excepcionalidad de la disposición de tal instru-

\footnotetext{
1 Santolaya Machetti, P., en El Régimen constitucional de los Decretos-Leyes, Tecnos, 1988 , p. 107, considera que «el Decreto-Ley se configura no como un instrumento excepcional, sino como algo no normal».
} 
mento. Es el caso de Soriano ${ }^{2}$, que entiende que en la primera sentencia del Tribunal Constitucional al respecto (29/1982, de 31 de mayo) se aprecia el reconocimiento del carácter excepcional del Decreto-Ley en el sistema de fuentes del derecho establecidas en la Constitución, debido fundamentalmente a lo que expresa en su Fundamento Jurídico $1 .^{\circ}$, mientras que en la segunda sentencia (6/1983, de 4 de febrero) queda diluido ese carácter excepcional. Dice lo siguiente la primera de las sentencias citadas:

«El Gobierno podrá dictar normas con rango de Ley (...), en los supuestos de extraordinaria y urgente necesidad (decretos-leyes), pero esta posibilidad se configura, no obstante, como una excepción al procedimiento ordinario...».

Sin embargo, el Tribunal declara en el mismo párrafo, recordado también en sentencias posteriores, que la reconocida posibilidad de utilización del Decreto-Ley «está sometida en cuanto a su ejercicio a la necesaria concurrencia de determinados requisitos que lo legitiman». Parece, por tanto, más conveniente centrar la atención en el grado y clase de cumplimiento de los requisitos que es exigido por el Alto Tribunal ${ }^{3}$, que en la mera formulación genérica acerca de su excepcionalidad.

Siguiendo este criterio, no pueden apreciarse en la jurisprudencia constitucional intenciones dispares respecto a la funcionalidad del Decreto-Ley, sino más bien una definición sucesiva, aún sin terminar, de su ámbito y límites. Cuestión distinta es la discrepancia que en la doctrina ha quedado plasmada, respecto a la postura adoptada por el Tribunal Constitucional ${ }^{4}$.

El uso excepcional del Decreto-Ley es legítimo cuando su ejercicio se verifica dentro de los límites que la Constitución establece. En este sentido se manifiesta desde el principio el Tribunal constitucional en su Sentencia 29/1982, de 31 de mayo:

2 SoRiano, J.E.: «Los Decretos-Leyes en la Jurisprudencia Constitucional española», $R A P$, núms. 100-102, 1983, pp. 454-455.

${ }^{3}$ Hay que expresar, no obstante, que el Tribunal Constitucional no abandona su consideración acerca de la excepcionalidad que envuelve la figura del Decreto-Ley. En su sentencia 29/86, de 20 de febrero, señala lo siguiente:

...«dada la excepcionalidad con que nuestra Constitución regula la figura del Decreto-Ley, sólo cuando concurra una causa suficiente de necesidad, adjetivada por las circunstancias de extraordinaria urgencia, puede el Gobierno utilizar este instrumento normativo...» (FJ 2).

${ }^{4}$ Vid. Salas, J.: «Los Decretos-Leyes en la teoría y en la práctica Constitucional», en Estudios sobre la Constitución Española. Homenaje al profesor Eduardo García de Enterría, Cívitas, 1991, pp. 273 y ss.

Astarloa Huarte-Mendicoa, I.: «Teoría y práctica del Decreto-Ley en el ordenamiento español», RAP, núm. 106, pp. 117 y ss.

PÉREZ ROYO, J.: «La distribución de la capacidad normativa entre el Parlamento y el Gobierno», en El Gobierno en la Constitución española y en los Estatutos de Autonomía, Diputación de Barcelona, 1985, p. 141. 
«Nuestra Constitución limita en un doble sentido la facultad excepcional que atribuye al Gobierno para promulgar, en forma de DecretoLey, normas con fuerza de Ley. Esta limitación viene dada, de una parte $(\ldots)$, por la exclusión de determinadas materias (...), que en ningún caso pueden ser objeto de regulación mediante Decreto-Ley; de la otra, por la conexión establecida entre esta facultad legislativa excepcional y la existencia de un presupuesto habilitante concreto: el caso de extraordinaria y urgente necesidad» (FJ 3$)$.

A pesar de la competencia de los órganos políticos, concretamente del Congreso de los Diputados, para fiscalizar, a través de su apreciación, la concurrencia del presupuesto habilitante para el ejercicio de la facultad legislativa excepcional, es competencia del Tribunal Constitucional rechazar la definición realizada por los órganos políticos en supuestos de uso abusivo o arbitrario de la figura del Decreto-Ley. Sin embargo, esta operación no tiene los lindes muy claros, de tal manera que el Tribunal Constitucional corre un cierto riesgo de entrar con sus apreciaciones en el terreno del juicio de oportunidad reservado al ámbito político.

En este sentido, el Tribunal Constitucional ha determinado las líneas básicas de la necesidad que debe concurrir para que el ejercicio de la posibilidad constitucional sea legítima.

En primer lugar, la necesidad exigible no es absoluta, entendiendo por tales aquellas en que puede existir un peligro inminente para el orden constitucional, de tal modo que la regulación a través de Decreto-Ley no es permitida sólo en forma totalmente excepcional. Por ello el Tribunal Constitucional señala que la solución adoptada por la Constitución es flexible y matizada, en cuanto se exige para su uso la concurrencia de una necesidad relativa respecto de situaciones concretas relacionadas con objetos gubernamentales que, por razones que son difíciles de prever, exigen una acción normativa inmediata, para la que no son servibles los procedimientos ordinario o incluso el de urgencia, de elaboración de las leyes. En este sentido, se considera que la Constitución contempla el Decreto-Ley como un instrumento que puede utilizarse para dar respuesta a las perspectivas cambiantes de la vida actual $^{5}$ y alcanzar los objetivos marcados para la gobernación del país.

La definición expansiva del campo así reservado al Decreto-Ley por la Constitución según el Tribunal Constitucional, para la satisfacción de necesidades relativas, configura un instrumento normativo de respuesta a cuestiones que se manifiestan en nuestro tiempo con carácter ordinario, a FJ.3.

SSTC 6/83 de 4 de febrero, FJ.5; 29/86, de 20 de febrero, FJ.2; 60/86 de 20 de mayo, 
la vez que admite la existencia de un ámbito de oportunidad política y técnica en la elección de dicha respuesta, sobre la que el Tribunal Constitucional, como ya ha dejado sentado desde la primera de sus sentencias al respecto (29/1982, de 31 de mayo, FJ 5), no tiene competencia para pronunciarse.

En segundo lugar, el carácter extraordinario con el que se adjetiva la necesidad en la Constitución, no proviene de la naturaleza del ámbito, que, como ha quedado expuesto, obedece a necesidades relativas provenientes de los objetivos de la gobernación del país, sino fundamentalmente de la dificultad o imposibilidad de prever las circunstancias que requieren una respuesta normativa inmediata.

En tercer lugar, la urgencia que debe acompañar a la necesidad, implica la inidoneidad del procedimiento legislativo ordinario o del procedimiento de urgencia para responder adecuadamente a las necesidades planteadas.

\section{II.2. Lo extraordinario}

Las necesidades sociales ordinarias son, o al menos deben ser, referencia e inspiración obligada de la particular perspectiva de los diferentes programas políticos. En este sentido, las leyes suponen un intermedio necesario para que el Gobierno pueda aplicar su programa político, en aras a la satisfacción de dichas necesidades y por tanto, el instrumento ordinario a su servicio. Las necesidades ordinarias componen el complejo ordinario de objetivos que el Gobierno pretende obtener. La identificación, determinación y formulación de dichas necesidades implican un ejercicio de reflexión, búsqueda y previsión que confluye y caracteriza al programa político. Consiguientemente el procedimiento legislativo ordinario es el cauce de incorporación de los fines que satisfarán, a través de su ejecución, las necesidades que son su presupuesto.

El Decreto-Ley pretende cubrir un espacio no cubierto por la Ley como instrumento jurídico de satisfacción de necesidades sociales ordinarias. Ese espacio está configurado por las necesidades que no pueden ser objeto de previsión, o que pueden ser difícilmente previsibles, pero que existen y se manifiestan de un modo ciertamente sorpresivo que requiere una acción imnediata.

Resulta evidente que, en ocasiones, la pericia de quien ostenta la responsabilidad de brindar esas respuestas normativas, influye notablemente en el significado y alcance de la imprevisibilidad, de tal modo que lo que para algunos es absolutamente imprevisible, para otros es una situación vista a lo lejos y por tanto esperada. En cualquier caso, parece necesario 
ponderar en cada supuesto, el grado de razonable imprevisibilidad que concurre a fin de reconocer la legitimidad en el uso del Decreto-Ley.

El Tribunal Constitucional se ha hecho eco de este factor de dificultad o imposiblidad de previsión, así como de la concurrencia compleja de circunstancias que impiden acudir a la vía legislativa ordinaria, para justificar la existencia del presupuesto habilitante. Así:

...«la utilización del Decreto-Ley mientras se respeten los límites del artículo 86 de la Constitución, tiene que reputarse como una utilización constitucionalmente lícita en todos aquellos casos en que hay que alcanzar los objetivos marcados para la gobernación del país, que, por circunstancias difíciles o imposibles de prever, requieren una acción normativa inmediata o en que las coyunturas económicas exigen una rápida respuesta» (STC 6/1983, de 4 de febrero, FJ 5).

«Nuestra Constitución (...) ha contemplado el Decreto-Ley como instrumento del que es posible hacer uso para ordenar situaciones que, por razones difíciles de prever, reclaman una acción legislativa inmediata, en un plazo más breve que el requerido por la tramitación parlamentaria de las leyes. La justificación del Decreto-Ley podrá darse en aquellos casos en que por circunstancias o factores, o por su compleja concurrencia, no pueda acudirse a la medida legislativa ordinaria, sin hacer quebrar la efectividad de la acción requerida, bien por el tiempo a invertir en el procedimiento legislativo o por la necesidad de la inmediatividad de la medida» (STC 111/1983, de 2 de diciembre, FJ 6).

...«la utilización del Decreto-Ley, mientras se respeten los límites del art. 86 de la Constitución, tiene que reputarse como una utilización constitucionalmente lícita en todos aquellos casos en que hay que alcanzar los objetivos marcados por la gobernación del país, que por circunstancias difíciles o imposibles de prever, requieren una acción normativa inmediata o en que las coyunturas económicas exigen una rápida respuesta» (STC 29/1986, de 20 de febrero, FJ 2). Reproducido también en la STC 60/1986, de 20 de mayo, FJ 3.

Por tanto, no es posible una utilización legítima del Decreto-Ley sobre cuestiones o situaciones que son fácilmente previsibles, o peor aún, que son sobrada y acreditadamente conocidas. Esta clase de hechos entran dentro de lo que anteriormente se ha denominado como necesidades ordinarias, para las que la Constitución, cuando así se requiera, reserva el procedimiento legislativo ordinario. La excepcionalidad en el uso del Decreto-Ley, requiere una necesidad acompañada de los adjetivos extraordinaria y urgente, sin que se pueda prescindir de ninguno de los dos. Lo contrario sería admitir como causa habilitante la concurrencia de cualquier necesidad.

Pueden plantearse dudas acerca del grado de imprevisibilidad requerido para un uso legítimo del Decreto-Ley, sin embargo existen indicios 
racionales de previsibilidad que pueden desvirtuar la pretendida existencia del presupuesto habilitante. Como señala ASTARLOA HUARTEMENDICOA, la extraordinariedad y la urgencia «no son términos sinónimos, en cuanto aquélla no se refiere tan sólo al ámbito temporal, sino más bien a una valoración cualitativa de la necesidad, que viene así descrita como importante, grave e imprevisible, teniendo en cuenta que, si la gravedad admite complicada calificación jurídica, la previsibilidad puede deducirse de datos como la existencia de proyectos anteriores, negociaciones previas (...), proposiciones registradas en sede parlamentaria $\mathrm{o}$, en general, la valoración de los diversos antecedentes del tema» ${ }^{6}$.

La admisión de las denominadas necesidades relativas como ámbitos susceptibles de ser regulados mediante Decreto-Ley no implica la desaparición de la exigencia de urgencia y extraordinariedad, aunque la interpretación del Tribunal Constitucional de este presupuesto haya supuesto la identificación de esas necesidades. Dicho con otras palabras, no sólo debe reconocerse eficacia al presupuesto habilitante, para el caso de que la interpretación quede decantada hacia la defensa del uso totalmente excepcional del Decreto-Ley, sino que también tiene su virtualidad cuando los ámbitos permitidos a dicha norma con rango de ley son necesidades relativas ${ }^{7}$. En este sentido resulta apropiado traer a colación la apelación

6 Astarloa Huarte-Mendicon, I.: «Teoría y práctica del Decreto-Ley en el ordenamiento espanol», $R A P$, núm. 106, p. 119. El autor entiende que la consideración por parte del Tribunal Constitucional de las necesidades relativas que se deducen de los objetivos gubernamentales, identifica la idea de necesidad con las de conveniencia y comodidad, abriendo posibilidades ilimitadas al Decreto-Ley, sólo acotadas por la interdicción de la arbitrariedad proclamada en el 9.3 de la Constitución (pp. 122-123).

Sin embargo, parece posible la estimación de esas necesidades de carácter relativo, y a la vez el respeto de la extraordinaria y urgente necesidad establecida en la Constitución, como límite efectivo en la utilización del Decreto-Ley.

7 SaLAS, J., en «Los Decretos-Leyes en la teoría y en la práctica constitucional», en Estudios sobre la Constitución Española, Homenaje al profesor Eduardo García de Enterría, tomo I, pp. 274 y 275, postula la inconstitucionalidad de aquel Decreto-Ley que «de haberse presentado como proyecto de ley a través de alguna de las modalidades procedimentales indicadas [se refiere al procedimiento de urgencia, aprobación en comisión con competencia legislativa plena, tramitación en lectura única] hubiera podido convertirse en Ley en un plazo tal que la necesidad que pretendiera satisfacer se mantuviera en pie y no se hubieran producido graves perjuicios [el subrayado no es original] para los intereses públicos en el lapso de tiempo que medie entre la presentación de aquel proyecto y su promulgación como Ley». El hecho de que el Tribunal Constitucional se haya decantado por la llamada «necesidad relativa», supone, a su juicio, la adopción de una distinta línea interpretativa que desemboca en la disposición por parte del Gobierno de poder apreciar discrecionalmente la concurrencia de dicho presupuesto, reservando el control de esa apreciación al Tribunal Constitucional, sólo cuando sea claramente abusiva o contraria.

En similar sentido Pérez Royo, J.: «La distribución de la capacidad normativa entre el Parlamento y el Gobierno», en El Gobierno en la Constitución Española y en los Estatutos de 
de LAVILLA a la innecesariedad de sustentar los pronunciamientos jurisdiccionales del Tribunal Constitucional, en valoraciones que supongan «cierta atenuación del sentido y del alcance con los que el artículo 86 confiere potestades normativas excepcionales al Gobierno» ${ }^{8}$.

\section{II.3. Lo urgente}

Los márgenes de discrecionalidad con que cuenta el Gobierno para la definición del presupuesto habilitante ${ }^{9}$, alcanzan obviamente al concepto y significado de urgencia, pero en la misma medida que le afectan los límites que la Constitución establece a ese margen de definición.

La urgencia, como antes se ha manifestado, adjetiva y caracteriza a la necesidad, por tanto debe entenderse ligada a ella, de tal modo que la apreciación gubernamental respecto a su concurrencia, no debe basarse en su propia voluntad, sino en la adecuación a la satisfacción de la nece$\operatorname{sidad}^{10}$.

La jurisprudencia del Tribunal Constitucional establece una doctrina en torno a la urgencia, que, en línea con la excepcionalidad planteada en el artículo 86, concibe el Decreto-Ley como un procedimiento excepcional alternativo a otros procedimientos legislativos, cuya utilización no es posible por su falta de adecuación a las necesidades de inmediatez que son exigidas. En ese sentido señala lo siguiente:

«EL T.C. podrá, en supuestos de uso abusivo o arbitrario, rechazar la definición que los órganos políticos hagan de una situación determinada como caso de extraordinaria y urgente necesidad, de tal naturaleza que no pueda ser atendida por la vía del procedimiento legislativo de urgencia» (STC 29/1982, de 31 de mayo, FJ 3).

Autonomía, Diputación de Barcelona, 1985, p. 141. Astarloa Huarte-MendicoA, I.: «Teoría y práctica del Decreto-Ley...», op. cit., p. 123.

8 Lavilla, L.: «Sobre los Decretos-Leyes» en Libro Homenaje al Profesor J.L. Villar Palasí, Cívitas, Madrid, 1989, p. 621.

${ }^{9}$ Para examinar el alcance del presupuesto habilitante desde la distinción entre discrecionalidad y conceptos jurídicos indeterminados, pueden verse, entre otros: GARCÍA DE ENTERRÍA, E. y Fernández, T.R.: Curso de Derecho Administrativo, I, Cívitas, 1995, pp. 134 y ss. SAlas, J.: Los Decretos-Leyes en la Constitución Española, Cuadernos Cívitas, 1979, pp. 29 y ss. DE Отто, I.: Derecho Constitucional. Sistema de fuentes, Ariel, 1995, pp. 197-198.

Sobre la elaboración doctrinal de tales categorías jurídicas deben citarse GARCÍA DE ENTERRÍA, E.: «La lucha contra las inmunidades del Poder en el Derecho Administrativo», RAP, 1962, núm. 38 y SAInz Moreno, F.: Conceptos jurídicos, interpretación y discrecionalidad administrativa, Cívitas, 1976.

${ }^{10}$ Santolaya Machetti, P.: El régimen constitucional de los Decretos-Leyes, op. cit., p. 110 . 
...«no se fija un plazo perentorio para dictar tal regulación, que habría de ser inferior al necesario para tramitar la deslegalización como proyecto de Ley por el procedimiento de urgencia» (STC 29/82, de 31 de mayo, FJ 6).

...«situaciones concretas de los objetivos gubernamentales, que, por razones difíciles de prever, requieren una acción normativa inmediata en un plazo más breve que el requerido por la vía normal o por el procedimiento de urgencia para la tramitación parlamentaria de las leyes» (STC 6/83, de 4 de febrero, FJ 5). Reproducido en la STC 111/1983, de 2 de diciembre, FJ 6 y 60/1986, de 20 de mayo, FJ 3.

...«regula la figura del Decreto-Ley (...) como instrumento en cuanto a su fuerza equivalente a la Ley, y utilizable cuando una necesidad calificada por las notas de lo «extraordinario» y lo «urgente» reclama una acción normativa que, por lo ordinario, compete al legislador, pero que precisamente por esa necesidad, y no poder ser atendida por una acción normativa emanada de las Cortes Generales, se autoriza al Gobierno, con un carácter de provisionalidad hasta tanto obtiene la convalidación...» (STC 111/83, de 2 de diciembre, FJ 4).

De esta manera la legitimidad de la utilización del Decreto-Ley no sólo depende de la propia necesidad, sino en esta concreta cuestión, depende también del tiempo que haya de invertirse en los procedimientos legislativos ordinarios ${ }^{11}$ y por tanto de si éstos resultan remedios adecuados para la inmediatez requerida de la acción normativa.

En nuestro ordenamiento, no es posible separar, en lo que entendemos como acción normativa, el hecho mismo de la actuación normativa de la aplicación material de su contenido. O por lo menos no es posible hasta el punto de desvirtuar la noción de urgencia exigida.

Esta posibilidad planteada y criticada en la doctrina italiana (Espósito y Raveraira, respectivamente ${ }^{12}$ ), tiene dos manifestaciones, como se encarga de resaltar SANTOLAYA MACHETTI:

Una de ellas, la posibilidad de dilatar en el tiempo la aplicación del contenido del Decreto-Ley.

Otra, la concurrencia del Decreto-Ley para dar satisfacción a necesidades que se consideran urgentes, pero que han surgido con mucha anterioridad a su promulgación, bien atribuyéndole efectos retroactivos, o sin dicha atribución.

11 Sobre la falta de legitimidad de los Decretos-Leyes, cuando se basan exclusivamente en la tardanza del Parlamento puede verse Di Ciolo, V.: Questioni in tema de Decreti-legge, I, Giuffrè, Milano, 1970, p. 230, y PALADIN, L.: «Gli atti con forza di legge nelle presenti esperienze costituzionali», Giurisprudenza Costituzionale, 1974, 1, p. 1.520, consultados por Santolaya Machetti, P., en El régimen constitucional de los Decretos-Leyes, op. cit.

12 Espósito, C.: «Decreto-Legge», en Enciclopedia del Diritto, 1962, pp. 844-5 y RAVERAIRA, M.: «Il problema del sindacato di costituzionalit sui presupposti della "necesit" et “urgenza” dei Decretilegge», Giurisprudenza Costituzionale, 1982, I, pp. 1433 y ss. 
Para el caso concreto que se va a analizar (Real Decreto-Ley 5/1996, de 7 de junio), no interesan las consideraciones al respecto de la dilación temporal en la aplicación del contenido normativo correspondiente, ni la atribución de efectos retroactivos, pero sí el hecho de la declaración como urgentes de necesidades surgidas, y desafortunadamente todavía hoy existentes, con mucha anterioridad a la fecha en que se promulga el Real Decreto-Ley citado.

El Tribunal Constitucional no ha tenido hasta la fecha, la oportunidad de manifestarse sobre tal cuestión, pero resulta evidente que el conocimiento anticipado, exageradamente anticipado, de una necesidad social, provoca razonablemente su conversión en un argumento programático de carácter político, y consiguientemente en un objetivo gubernamental, que destruye la notas de imprevisibilidad y urgencia en el sentido exigido constitucionalmente.

Podría argumentarse que precisamente el hecho de que exista una situación de necesidad social, cuya solución todavía está pendiente, avala aún más la decisión del Gobierno de utilizar un instrumento excepcional que asuma el tratamiento y respuesta inmediata de tal necesidad. Sin embargo, esa concepción de la urgencia, no está cohonestada con el presupuesto habilitante que la Constitución exige, sino más bien con un sentido de urgencia relacionado con la voluntad gubernamental, que son cuestiones absolutamente distintas.

No es procedente excluir la relación entre necesidades sociales e idoneidad del procedimiento legislativo ordinario, y por consiguiente la utilización alternativa del Decreto-Ley para conseguir la promulgación de una serie de medidas de respuesta inmediata a tales necesidades, cuando éstas son reconocibles y reconocidas como un problema sentido y encajado en la sociedad a través del transcurso del tiempo. No es legítimamente posible el uso de dicho instrumento jurídico, cuando esas necesidades, largamente vividas como problemas sociales, han sido y están siendo objeto de tratamiento legislativo, aunque pueda entenderse inadecuado, lo cual, a estos efectos, resulta irrelevante.

\section{II.4. El examen del Real Decreto-Ley 5/1996, 7 de junio, de medidas liberalizadoras en materia de suelo}

El objeto de este Decreto-Ley entra dentro de lo que se ha venido en denominar necesidades relativas, es decir situaciones concretas relacionadas con objetivos gubernamentales, como son en este caso el abaratamiento del suelo, el incremento de su oferta y así el consiguiente incremento de la oferta de vivienda, con la correlativa bajada de precios. 
Sin embargo, el tratamiento de esta clase de necesidades es el denominador común de la acción legislativa ordinaria que, a través del impulso político, convierte los postulados programáticos en fines del ordenamiento jurídico y en ese sentido en objetivos de las Administraciones públicas para transformar la realidad.

Por ello, la Constitución, como se ha venido señalando, exige una especial cualificación de esas necesidades, a fin de que la concurrencia del Decreto-Ley sea posible y legítima. Si esa cualificación no existe, es decir si no se da el presupuesto habilitante requerido, tendremos que situar esas necesidades en el ámbito de lo ordinario, es decir en el ámbito atendible por los procedimientos ordinarios que la Constitución establece al efecto. El supuesto al que se está haciendo referencia no cumple con los requisitos constitucionalmente exigidos y por ello debe reputarse su tratamiento a través de Decreto-Ley como contrario a la Constitución.

En lo que se refiere al carácter extraordinario de la necesidad, para su reconocimiento debe existir al menos, una cierta dificultad en la previsión de las circunstancias que aconsejan la promulgación del DecretoLey. El ordenamiento jurídico urbanístico acredita fehacientemente desde sus postulados, que tal imprevisibilidad no existe, sencillamente porque durante al menos dos décadas se está ocupando de la regulación del precio del suelo, del suelo urbanizado disponible y de su repercusión en el mercado de la vivienda. En este sentido, no sólo hay que considerar el ordenamiento estatal, sino también la extraordinaria dedicación, al menos legislativa, de las Comunidades Autónomas al tratamiento de este problema $^{13}$.

Por tanto, no sólo no estamos ante una clase de problemas sorpresivamente manifestados y cuya falta de previsión sobre ellos nos empuja a dar una respuesta normativa adecuada para su solución, sino que se trata de un problema largamente padecido, largamente tratado, y actualmente regulado con una ordenación recientemente aprobada.

Además de estos antecedentes, verdaderamente relevantes, se puede añadir como prueba de falta de imprevisibilidad, la presentación por parte del propio Grupo Parlamentario Popular de una Proposición de Ley de modificación del Real Decreto Legislativo 1/1992, de 26 de junio, por el que se aprobó el Texto Refundido de la Ley sobre el Régimen del Suelo y Ordenación Urbana ${ }^{14}$, que por cierto, como desta-

13 La mención de la legislación existente en materia de suelo y vivienda resultaría abrumadora.

14 Boletín Oficial de las Cortes Generales, de 21 de octubre de 1995, núm. 155-1. 
ca JIMENEZ DE CISNEROS CID no incluía ninguna de las medidas contenidas en el Decreto-Ley ${ }^{15}$.

No quiere decirse que siempre que exista una ordenación normativa de una situación potencialmente regulable a través de Decreto-Ley, la existencia de aquélla sea un obstáculo para el citado tratamiento, pero desde luego la utilización del Decreto-Ley de acuerdo a las exigencias de la Constitución, implica la aparición de una situación nueva, cuya satisfacción no es producida a través de la regulación preexistente y sus notas de imprevisibilidad, gravedad, importancia y urgencia avalan la promulgación del Decreto-Ley. Como es obvio, con el caso que nos ocupa, no se dan estas circunstancias.

En lo que se refiere a la pretendida urgencia, es preciso también expresar algunas consideraciones. El urbanismo, tanto por su propia naturaleza, como por los caracteres del ordenamiento que lo regula, destila una total incompatibilidad con la urgencia. Los procesos de maduración que se producen en el urbanismo, desde que se diseñan y planifican originariamente, hasta que se desarrollan y llevan a la realidad de los hechos, condicionan y caracterizan la naturaleza de tal materia. La pretensión de encajar el concepto de urgencia como un elemento consustancial del entramado ordinamental urbanístico, es desconocer su propia naturaleza. Dicho de otro modo, la normal utilización de los procedimientos previstos en el ordenamiento urbanístico, implican el cumplimiento de fases y trámites, cuya consecuencia más inmediata es el consumo de tiempo en una cantidad que es en todo punto incompatible con la urgencia ${ }^{16}$. Incluso en supuestos en que concurren razones de «urgencia o excepcional interés público» (artículo 244.2 Real Decreto Legislativo 1/1992, de 26 de junio), y debido a ellas se permite la separación de las vinculaciones del planeamiento, es preceptiva la tramitación de la modificación o revisión del planeamiento, conforme a las determinaciones de la legislación urbanística. Por lo cual, la única urgencia entendible, sería aquélla que referida a una concreta actuación, tratase de evitar la aplicación del ordenamiento urbanístico, precisamente por la urgencia concurrente en el supuesto de hecho.

Sin embargo, el Decreto-Ley 5/1996, de 7 de junio, innova el ordenamiento jurídico, modificando el existente, basándose en una pretendida

15 Jiménez DE Cisneros CID, F.J.: «Los efectos de la "liberalización del suelo" sobre el Texto Refundido de la Ley del Suelo de 1992», Revista de Derecho Urbanístico y Medio Ambiente, julio-agosto-septiembre, 1996, p. 15.

${ }^{16}$ No se pretende en absoluto, una apología del modelo existente, sino más bien poner de manifiesto la condición natural de tal ordenamiento para entender en sus justos términos las relaciones entre éste y la urgencia. 
urgencia que nunca llegará a satisfacerse por la propia naturaleza de la materia. El proceso temporal en que quedan inmersas sus medidas, -reducción del aprovechamiento lucrativo susceptible de apropiación por la Administración del 15 al 10\%, identificación jurídica del suelo urbanizable programado y no programado, incluso la agilización de la tramitación y aprobación del planeamiento-, supone la relativización, incluso la neutralización, de la pretendida urgencia con la que se legisla en la materia.

Es difícil, si no imposible, pretender legítimamente la utilización de un procedimiento legislativo excepcional como es el previsto en el artículo 86.1 de la Constitución, basado, entre otras cuestiones, en una necesidad urgente, cuando la aplicación de su contenido no va a responder con tal carácter a las necesidades planteadas por el Gobierno como habilitantes del Decreto-Ley ${ }^{17}$.

Todas estas consideraciones tienen su correlativa expresión en la Exposición de Motivos del mencionado Decreto-Ley que, sin ser una excepción en lo que se refiere a la falta de suficiente motivación de los Decretos-Leyes, contiene una más que insuficiente mención a las necesidades habilitantes ${ }^{18}$ y una inadecuada relación de las medidas adoptadas con el sentido último de la situación definida, cuestión ésta sobre la que incidiremos más adelante.

El Tribunal Constitucional desde la primera de sus sentencias, ha dejado clara su exigencia de que la definición de la situación habilitante sea «explícita y razonada». De este modo el Alto Tribunal señala lo siguiente:

«El T.C. podrá, en supuestos de uso abusivo o arbitrario, rechazar la definición que los órganos políticos hagan de una situación determinada como caso de extraordinaria y urgente necesidad, de tal naturaleza que no pueda ser atendida por la vía del procedimiento legislativo de urgencia. Es claro que el ejercicio de esta potestad de control del Tribunal implica que dicha definición sea explícita y razonada y que exista una conexión de sentido entre la situación definida y las medidas que en el

17 No me refiero, como se habrá podido apreciar al sentido en que EsPósito distinguía entre norma y contenido de la norma. Vid. Espósıto, C.: Enciclopedia del Diritto, «Voz Decreto Legge», Guiffrè Editore, 1962, p. 844.

18 La Exposición de Motivos señala como justificación del Decreto-Ley lo siguiente:

«Dada la situación del mercado de suelo y la vivienda, se hace necesaria la aprobación de unas primeras medidas que ayudarán a incrementar la oferta de suelo con la finalidad de abaratar el suelo disponible. Las modificaciones propuestas de la legislación urbanística están también orientadas a simplificar los procedimientos y a acortar los plazos vigentes. Se conseguirá así, avanzar en el logro del objetivo público de garantizar con mayor facilidad el acceso a la vivienda y a reducir la enorme discrecionalidad ahora existente». 
Decreto-Ley se adoptan». (STC 29/1982, de 31 de mayo, FJ 3. Reproducido en la STC 111/83, de 2 de diciembre, FJ 5).

En su sentencia 29/1986, de 20 de febrero, valora la justificación realizada por el Gobierno, declarando:

«En el presente caso, el Gobierno justificó la adopción del Real Decreto-Ley 8/1983 (en su Exposición de Motivos), en la subsistencia de los problemas de la reconversión industrial así como en la inexistencia de una normativa adecuada para afrontarlos, una vez extinguida la vigencia de la Ley 21/1982, de 9 de Junio...» (FJ 2).

En cualquier caso, parece lógico pensar que la existencia o inexistencia de motivación, no puede constituir el elemento fundamental de decisión acerca de la constitucionalidad o no del respectivo Decreto-Ley, pero sí debe tenerse como un indicio más a ser valorado globalmente con el resto de circunstancias que concurran en el supuesto. Es posible encontrar legítimas habilitaciones para el uso del Decreto-Ley acompañadas de paupérrimas motivaciones, y al revés, extensas y artificiosas argumentaciones acerca de la justificación para dictar un Decreto-Ley que no dispone de presupuesto habilitante.

Ciertamente en este sentido se ha manifestado el Tribunal Constitucional, cuando en su sentencia 60/1986, de 20 de mayo, expresa lo siguiente:

«Con independencia de que tal motivación resulte o no convincente, lo que nos toca indagar ahora es si concurre o no realmente el presupuesto de hecho habilitante del Decreto-Ley impugnado, es decir, el caso de extraordinaria y urgente necesidad» (FJ 3).

Por tanto, cabe decir que la motivación de la justificación existente, constituirá un elemento más de juicio o referencia para el Alto Tribunal, en el contexto de una valoración conjunta.

Por otra parte, ¿qué carácter tiene la relación existente entre las medidas adoptadas y el sentido último de la situación definida como presupuesto habilitante?

El Tribunal Constitucional se ha autolimitado en la función de fiscalizar esa relación de adecuación entre situación habilitante y medidas adoptadas. En este sentido se ha decantado, cuando ha establecido que:

«El Tribunal no podría, sin traspasar las fronteras de su función y a la vez de su responsabilidad, inmiscuirse en la decisión de gobierno, pues si así se hiciera quedarían alterados los supuestos del orden constitucional democrático» (STC 111/1983, de 2 de diciembre, FJ 5).

Sin embargo en la delimitación de las fronteras de su función, se ha pronunciado con un carácter confuso que se ha interpretado y traducido 
como una ampliación de los márgenes de discrecionalidad a disposición del Gobierno.

Realmente, cuando el Tribunal Constitucional (Sentencia 29/1982, de 31 de mayo) expresa respecto al contenido dispositivo del Real DecretoLey, que el Gobierno no está autorizado a incluir en él «cualquier género de disposiciones: ni aquéllas que, por su contenido y de manera evidente, no guarden relación alguna, directa ni indirecta, con la situación que se trata de afrontar...» (FJ 3) está utilizando una fórmula más amplia y omnicomprensiva de la que posteriormente hace uso en el Fundamento Jurídico 5 de la misma sentencia, cuando expresa que «no es competencia del T.C. el pronunciarse sobre la mayor o menor oportunidad técnica de las medidas que en el mismo se establecen (...), pues ello se enmarca en la actividad propia del debate parlamentario, y la defensa en el mismo de los distintos criterios políticos que al respecto se formulen...».

Son formulaciones ciertamente distintas. Será verdaderamente difícil que el contenido de un Decreto-Ley no guarde, y además de forma evidente, ninguna relación directa ni indirecta con el presupuesto habilitante. Aunque sólo fuera porque presupuesto habilitante y medidas perteneciesen a una misma materia o sector de actividad administrativa, ya tendríamos cosida una relación habilitante y legitimadora de la normación mediante Decreto-Ley.

Parece indudable que una formulación de este tenor excede con mucho a la denominada, exigida y repetida «conexión de sentido» ${ }^{19}$ necesaria para que la relación entre la situación definida y las disposiciones adoptadas sea adecuada. Expresado de otra manera, sin necesidad de pronunciarse sobre la mayor o menor oportunidad técnica de las medidas que en él se establezcan, es posible realizar un control acerca de si existe o no una conexión de sentido entre la situación definida y las disposiciones adoptadas.

En el supuesto que nos ocupa, tal vez debiera señalarse previamente que no estamos ante un Decreto-Ley, sino ante dos Decretos-Leyes, bajo la envoltura de uno solo, dado que existen situaciones que ninguna relación poseen entre sí y que a su vez disponen de preceptos separados pretendidamente referibles a cada una de ellas.

En lo referente a la materia de suelo la Exposición de Motivos como ya se ha señalado, identifica como objetivo o situación habilitante «abaratar el suelo disponible», que según se añade en la misma Exposición se pretende conseguir mediante el incremento de la oferta de suelo.

19 SSTC 29/82, de 31 de mayo, FJ 3; 111/83, de 2 de diciembre, FJ 5. 
Una razonable conexión de sentido entre el objetivo perseguido, como es el abaratamiento del suelo disponible, y las medidas adoptadas exigiría que éstas actuasen en la estructura de costes o en la estructura del mercado, de tal manera que, bien porque se rebajen aquéllos o porque se procure la incorporación masiva o significativa de suelos al mercado, se llegue al descenso deseado de los precios. Cualquier otra medida no parece que pueda reputarse como incluida en esa manifestada por el Tribunal Constitucional conexión de sentido.

Conforme a tal criterio no parece que los artículos 1,3 y 4 puedan entenderse comprendidos en esa conexión de sentido ${ }^{20}$.

Tal consideración no debe ser entendida en ningún caso, como contraria a la postulada interdicción de realizar valoraciones en torno a la mayor o menor oportunidad técnica de las medidas, para alcanzar el objetivo previsto como es el abaratamiento del suelo. El análisis suficiente y necesario para determinar si existe esa conexión de sentido exigida, requiere un esfuerzo de contraste que, sin entrar en una valoración acerca de su idoneidad técnica, permita concluir sobre la relación existente ${ }^{21}$.

Una valoración sobre la oportunidad técnica de las medidas implicaría el rechazo de todo el Decreto-Ley, por cuanto es razonable pensar que tales normas, por sí mismas, no van a lograr el objetivo que les mueve y justifica.

En esta línea de razonamiento, parece evidente que la norma que modifica el «aprovechamiento y cesión de suelo a los Ayuntamientos» incide en el cuadro de costes del propietario de suelo, por ello podría ser reputable, sin perjuicio de lo ya manifestado en torno a la extraordinaria y urgente necesidad, como conectada con el sentido de la situación defini$d a^{22}$, sin embargo, técnicamente es rechazable, porque como el tiempo se encargará de corroborar, es claramente inidónea para lograr, por sí sola, o

20 Véanse en Addenda.

${ }^{21}$ De cualquier forma, hay que tener presente que cuando falte la conexión de sentido, no será posible encontrar tampoco idoneidad técnica en las medidas que se dicten para el tratamiento de las necesidades a que respondan. La conexión de sentido debe entenderse como un estadio inicial al acierto técnico de las medidas, de tal modo que es un requisito previo ineludible.

De este modo, es posible encontrar supuestos en que, dándose esa conexión de sentido, no se produzca la pertinente cualidad técnica que sea precisa para la adecuada satisfacción de las necesidades manifestadas, cuestión en la que no cabe la intervención del Tribunal Constitucional, como ha quedado expuesto.

22 Aunque suponga eliminar lo que FERnÁndez RodRÍGUEZ, T.R., en «Informe sobre la Ley 8/1990, de 25 de julio, y sobre el Anteproyecto de Texto Refundido de la legislación del suelo», Revista de Derecho Urbanístico, núm. 129, p. 22, identifica como el único elemento de la Ley 8/1990 «que todos sin excepción han asumido con entusiasmo: la exigencia de cesión del 15 por 100 del aprovechamiento». 
acompañada tal como se regula en el Decreto-Ley, el incremento de la incorporación de suelos al mercado, en este caso por una disminución de costes del propietario, y consiguientemente abaratar sus precios.

Este razonamiento es de aplicación también al artículo 1. Si se pone en relación este artículo con la Disposición Transitoria ${ }^{23}$, se puede apreciar que no se produce ninguna incidencia en el mercado de suelo y más concretamente en el lado de la oferta. Nuevamente debe apuntarse que no se trata de una valoración técnica, acerca de si la incidencia ocasionada es adecuada, idónea u oportuna para la consecución de los objetivos planteados, sino por el contrario consiste en la constatación de que no se produce ningún efecto en relación con el objetivo pretendido, lo cual es consecuencia de la falta de conexión de sentido ${ }^{24}$.

Las siguientes razones que se expresan, avalan ese pronunciamiento:

Primera. El Decreto-Ley no contiene ninguna disposición respecto al suelo que sea necesario y, consecuentemente, deba clasificarse como urbanizable, sino que se limita a identificar el suelo urbanizable programado con el suelo urbanizable no programado y remite al planeamiento general como la vía pertinente para la declaración de los suelos que deben ser urbanizados.

Segunda. El mantenimiento del valor normativo de los planes vigentes de acuerdo con el ordenamiento anterior a la reforma operada por el Decreto-Ley, y su extensión a los procedimientos de elaboración, modificación o revisión ya iniciados, confirma la oferta que en éstos se haya realizado, sin ninguna incidencia del Decreto-Ley al respecto.

Por tanto, puede concluirse que el Decreto-Ley produce, como derecho supletorio, para los Planes Generales futuros la identificación de dos clases de suelo, que, con anterioridad a su promulgación, tenían regímenes jurídicos diferentes, pero nada determina respecto a la cantidad de suelo urbanizable que tales Planes deben clasificar como urbanizables. Por lo cual, regula una cuestión que no tiene conexión de sentido con el objetivo que dice pretender el Decreto-Ley.

Si el Decreto hubiese impuesto algún estándar cuantitativo de clasificación de suelo urbanizable, habría logrado esa conexión de sentido que le falta, por su incidencia en la cantidad de suelo clasificado. Ello no impediría su rechazo desde una perspectiva puramente técnica, perspectiva que, como se ha venido señalando, no estaría disponible para el Tribunal

23 Véase en Addenda.

24 Obviamente relación indirecta sí existe, en la medida en que estamos tratando de problemas incluidos en un ámbito común, como es el urbanismo, lo cual no debe considerarse, como ya se ha señalado, equivalente a una relación suficiente de conexión. 
Constitucional, pues se trataría de la asunción de una «responsabilidad que no corresponde a su función, y entrañaría una injerencia en una decisión política que sólo al Gobierno - con el control parlamentariocorresponde» (STC 111/1983, de 2 de diciembre, FJ 7).

Sería técnicamente rechazable porque el problema actual no se identifica con la mayor o menor oferta de suelo clasificado, es decir con la clasificación del suelo a través de los instrumentos de planeamiento, sino con la oferta de suelo debidamente calificado y urbanizado, geográficamente distribuido de acuerdo con la demanda, es decir se identifica con el desarrollo y ejecución del planeamiento ${ }^{25}$.

Comentarios similares han de hacerse respecto a los artículo 3 y 4 . En estos casos, la falta de adecuación del presupuesto habilitante con las medidas dictadas, se aprecia desde la propia redacción de la Exposición de Motivos efectuada por el Gobierno.

Recordemos que es «la situación del mercado de suelo y la vivienda» la que hace necesaria «la aprobación de unas primeras medidas que ayudarán a incrementar la oferta de suelo con la finalidad de abaratar el suelo disponible». Esta parca declaración pretende justificar la promulgación de su parte dispositiva, pero no de toda, porque desde la propia Exposición de Motivos se añaden párrafos que intentan abarcar justificadoramente al resto de preceptos dictados.

No se dispensa ninguna cobertura específica al artículo 2, porque se entiende que la mera alusión al abaratamiento del suelo disponible, está implicando al contenido del artículo 2. Sin embargo, eso no ocurre con el resto de preceptos (1, 3 y 4), por ello precisamente se añade que las modificaciones propuestas de la legislación urbanística «están también orientadas a simplificar los procedimientos y a acortar los plazos vigentes». Lo cual no debe considerarse como un presupuesto habilitante, sino como la reproducción en la Exposición de Motivos del contenido dispuesto en los mencionados preceptos. Con dicha técnica cualquier contenido normativo disfrutaría del reconocimiento de la conexión de sentido, pues se limitaría a ser fiel reproducción del anuncio realizado en la motivación. Parece evidente que la motivación no es eso, sino la identificación de los móviles, de las necesidades que provocan y aconsejan tal normación.

La relación de adecuación, por tanto, entre el abaratamiento del suelo disponible y, en su caso, el incremento de la oferta de suelo, con la re-

25 Vid. LóPez ToledAno, M A.: «Reflexiones acerca de la supresión de la distinción entre suelo urbanizable programado y suelo urbanizable no programado establecida en el Real Decreto-Ley 5/1996, de 7 de junio, de Medidas liberalizadoras en materia de suelo y colegios profesionales», RDUMA, julio-agosto-septiembre, 1996, pp. 70 y ss. 
ducción de los plazos de tramitación del planeamiento urbanístico y los órganos competentes para su aprobación es inexistente.

\section{II.5. Los efectos de la nulidad del cuestionado Decreto-Ley}

Del artículo 86 de la Constitución puede deducirse que aprobado un Decreto-Ley por el Gobierno, y debidamente publicado en el Boletín Oficial del Estado, surte efectos en el ordenamiento jurídico como una norma jurídica provisional, dotada de valor y fuerza de Ley.

La doble vía que, a efectos de fiscalización del Decreto-Ley, ha establecido el mencionado artículo 86, en sus apartados segundo y tercero, se ha decantado en la práctica parlamentaria, como es sabido, de manera sucesiva, en vez de alternativa, de tal manera que es preciso el previo pronunciamiento favorable, para su tramitación como proyecto de Ley por el procedimiento de urgencia.

Por tanto, si una vez obtenido tal pronunciamiento favorable, se decide proseguir con el procedimiento legislativo indicado, el resultado de tal operación, será a todos los efectos una Ley formal, que sustituirá al Decreto-Ley en el ordenamiento jurídico.

En sentido contrario, como ya ha dejado fundamentado el Tribunal Constitucional, en los casos en que el Congreso de los Diputados se haya limitado a homologar el Decreto-Ley sin emprender el procedimiento legislativo de urgencia, se consolida su eficacia jurídica como tal Decreto-Ley. Así:

...«en aquellos supuestos en que el Congreso de los Diputados se haya limitado a ejercitar sus competencias fiscalizadoras contempladas en el apartado $2 .^{\circ}$ del artículo 86 de $\mathrm{CE}$ sin acudir a la vía del número $3 .^{\circ}$, no puede considerarse que el Decreto-Ley se haya convertido en Ley formal del Parlamento, tras el acuerdo de convalidación, sino únicamente que se ha cumplido con el requisito constitucional del que dependía la pervivencia en el tiempo, con fuerza y valor de Ley, de la disposición producto del ejercicio de la potestad normativa extraordinaria que al Gobierno le reconoce la Constitución. En otras palabras, el Decreto-Ley no se transforma en Ley, es decir, no cambia su naturaleza jurídica. Esta situación es la misma en que se encuentra el Decreto-Ley en los supuestos en que se acuda a su tramitación como proyecto de Ley en el lapso de tiempo que transcurre entre la convalidación de totalidad como Decreto-Ley (...) y la publicación en el Boletín Oficial del Estado de la Ley resultante de la referida tramitación como proyecto de Ley por procedimiento de urgencia (...)» (STC 29/82, de 31 de mayo, FJ 2).

La tramitación del Decreto-Ley como proyecto de Ley posibilita, como se ha dicho, su conversión en Ley formal y consiguientemente, 
como ha señalado el Tribunal Constitucional y se ha encargado de destacar SANTOLAYA MACHETTI ${ }^{26}$, la sustitución de la provisionalidad del contenido normativo del Decreto-Ley, por la vigencia indefinida o estabilidad de la Ley formal. Ahora bien, debe tenerse en cuenta que el Decreto-Ley y, en su caso, la Ley formal tienen una existencia separada ${ }^{27}$, en la que caben distintas posibilidades que abonan esta separación. Por una parte, la Ley que sustituye al Decreto-Ley no absorbe necesariamente los vicios que haya podido tener el Decreto-Ley. Es tan posible que se reproduzcan las razones de inconstitucionalidad del Decreto-Ley en la Ley que lo sustituya como lo contrario, bien porque ésta elimine dichas razones o bien porque los motivos para postular la inconstitucionalidad de aquél, no son causa de inconstitucionalidad de la Ley. Por otra parte, la Ley formal no puede sanar retroactivamente, aunque lo pretenda, los vicios que se hayan podido producir originariamente en el Decreto-Ley. Como señala SORIANO, «se trataría de un acto realizado al amparo de una norma (la ley de sustitución) que persigue un acto contrario al Ordenamiento jurídico (integrado, en tal caso, por la sentencia del Tribunal Constitucional), por lo que se crea un evidente punto fraudulento de conexión que, por tanto, no impedirá la debida aplicación de la norma (la sentencia del Tribunal Constitucional) que se hubiera tratado de eludir» 28 .

Sin embargo, aunque su discurso parte de la preexistencia de una sentencia del Tribunal Constitucional al momento de promulgación de la ley de sustitución, también deben entenderse comprendidos en la posibilidad del juicio de constitucionalidad, los supuestos en que se haya dictado la ley de sustitución con anterioridad al pronunciamiento del Tribunal Constitucional sin que en ningún caso deba limitarse su fallo por el hecho de que se trate de una norma derogada o pretendidamente sanada con carácter retroactivo.

En este sentido, el Tribunal Constitucional, en su sentencia 111/83, de 2 de diciembre, rechaza la identificación de la relación entre DecretoLey y Ley de sustitución, con cualesquiera otras producidas mediante la derogación de una ley por otra posterior. Se manifiesta del siguiente modo:

26 Santolaya Machetti, P.: El régimen constitucional de los Decretos-Leyes, op. cit., 136 y ss.

${ }^{27}$ Vid. Astarloa Huarte-MendicoA, I.: «Teoría y práctica del Decreto-Ley en el ordenamiento español», op. cit., pp. 157-158.

28 SoRIANO, J.E.: «Los Decretos-Leyes en la jurisprudencia constitucional española», op. cit., p. 466. 
«El problema aquí planteado no es idéntico al que surgiría en un supuesto recurso directo de inconstitucionalidad contra una ley que, aunque vigente en el momento de haberse interpuesto aquél, hubiera sido posteriormente derogada; ni tampoco podrían identificarse entre sí estos dos últimos supuestos, pues el primero perseguiría el control abstracto, mientras que el segundo buscaría un control concreto, y, por consiguiente, aunque tanto el recurso como la cuestión tienen por objeto el enjuiciamiento de normas, en uno y otro podrían justificarse soluciones distintas, en cuanto a la desaparición de la razón del proceso, pues mientras en el recurso directo la derogación por lo común extinguirá el objeto, en la cuestión de inconstitucionalidad la solución puede ser otra por cuanto la validez de la norma — aún derogada - puede requerir un juicio de constitucionalidad. El supuesto del artículo 86.3 y la sustitución del Real Decreto-Ley por la Ley con una eficacia retroactiva que no es el caso examinar en este momento ofrece unas particularidades que impiden extender a él las conclusiones que pudieran inferirse de lo que acabamos de decir, desde las dos vertientes del control abstracto y del control concreto» (FJ 2).

En estos supuestos, por tanto, es posible seguir adelante con la impugnación del Decreto-Ley a pesar de que haya sido sustituido.

«Que el control del Decreto-Ley en cuanto tal no está impedido por el hecho de la novación operada por la Ley, siguiendo lo que dispone el artículo 86.3, es algo fuera de duda, pues ha de considerarse constitucionalmente legítimo que en defensa de la Constitución, para velar por la recta utilización del instrumento previsto para los casos que señala el artículo 86.1, los sujetos u órganos legitimados para promover el recurso de inconstitucionalidad, concreten al Decreto-Ley, sin atraer al proceso la Ley ulterior, la impugnación. El interés constitucional que mueve a los recurrentes es así el de ajustar el uso del instrumento del Decreto-Ley hacia el cauce del artículo 86.3, y por otro, no puede quedar sin enjuiciamiento acudiendo a la idea — que nada autoriza— de gravar a los recurrentes con la carga de impugnar la Ley, como presupuesto para enjuiciar los vicios que el Decreto-Ley pudiera tener en cuanto tal. Pudiera acaso pensarse que una eficacia retroactiva de la Ley que diera cobijo a los efectos producidos por el Decreto-Ley puede privar de sentido a la impugnación dirigida, y ceñida por la voluntad de los parlamentarios recurrentes al Decreto-Ley, mas esto no es así, pues sin cuestionar ahora si un vicio en origen por utilización del instrumento del Decreto-Ley, contra lo que previene el artículo 86.1, puede comunicar efectos invalidatorios, es lo cierto que el velar por el recto ejercicio de la potestad de emitir Decretos-Leyes, dentro del marco constitucional, es algo que no puede eludirse por la utilización del procedimiento del artículo 86.3» (FJ 3).

No obstante, en la misma sentencia se producen algunas contradicciones en lo que se refiere al reconocimiento de cierta eficacia sanatoria de la ley de sustitución: 
...«en un procedimiento legislativo que tiene su origen en un DecretoLey se culmina con una Ley que sustituye - con los efectos retroactivos inherentes a su objeto- al Decreto-Ley. El Decreto-Ley llevaba dentro de sí — al acudirse a la vía del artículo 86.3- el límite de su vigencia. Con estas precisiones es de donde debe examinarse si la conversión del Decreto-Ley en Ley priva de contenido al proceso o, en otra hipótesis, que es la que compartimos, reduce su ámbito litigioso. La otra alternativa, cual es la vinculación al proceso incoado, esto es, a la situación legislativa que configuró la pretensión sin operarse transformación alguna, no es aceptable, pues ni el proceso congela las facultades legislativas ni la definición y alcance del litigio puede entenderse perpetuado al momento de su plateamiento, ajeno a las vicisitudes posteriores que resulten, en general, del ejercicio de potestades legislativas» (FJ 2).

Precisamente en este sentido se manifestó, entre otras cuestiones, el voto particular formulado en la mencionada sentencia:

«La relación entre ambas normas puede ser entendida de dos maneras diferentes: bien considerando que el Decreto-Ley y la Ley posterior son dos normas distintas, bien estimando que representan dos momentos de la misma norma. Estas dos concepciones llevan a consecuencias divergentes. La primera de ellas obliga a concluir que, por tratarse de dos normas distintas, la impugnación del Decreto-Ley no se extiende a la Ley, cuya constitucionalidad, en consecuencia, no podrá ser examinada por impedirlo así la naturaleza del recurso de inconstitucionalidad y más precisamente, y a contrario, el artículo 39.1 de la LOTC. También conduce ineludiblemente a la conclusión de que la Ley carece de efecto alguno sobre el Decreto-Ley anterior, al que deroga, por lo que subsisten los vicios que éste efectivamente tuviera en el momento anterior a la derogación. La segunda concepción permite entender que la Ley posterior subsana en alguna medida los vicios del Decreto-Ley, pero, lógicamente, obliga a considerar que la impugnación de éste incluye también la de aquélla, ya que la Ley no es sino una prolongación en otra forma del Decreto-Ley.

\section{(...)}

La opinión de la que disentimos oscila entre estas dos concepciones incompatibles, aceptando de cada una de ellas tan sólo una consecuencia y negando la otra. Estima, de una parte, que la impugnación del DecretoLey no arrastra necesariamente la impugnación de la Ley, pero al mismo tiempo, mediante alusiones a la "retroactividad" de esta Ley, cuyo alcance como norma determinante de la expropiación hace retroceder hasta el momento de la promulgación del Decreto-Ley, atribuye implícitamente a la Ley eficacia para sanar los vicios formales del Decreto-Ley.

Por nuestra parte entendemos que el Decreto-Ley, que se encontraba vigente en el momento de interponer el recurso de inconstitucionalidad, es una norma distinta de la Ley posterior, pues de otro modo desaparecerían las limitaciones que el artículo 86.1 de la Constitución impone al Decreto-Ley. Por ello, a nuestro parecer, si bien en ningún caso podría ser 
enjuiciada la Ley posterior no recurrida por impedirlo el artículo 39.1 de la LOTC, la sentencia, en cambio, debió extenderse al enjuiciamiento de la totalidad del Decreto-Ley, con objeto de determinar su conformidad o disconformidad con la Constitución, cuya supremacía corresponde preservar a este Tribunal en caso de recurso, de acuerdo con el artículo 27.1 de su Ley Orgánica» (FJ 1).

El Decreto-Ley que nos ocupa fue sometido a debate y votación de totalidad por el Congreso de los Diputados, en su sesión del día 20 de junio de 1996 , en la que se acordó su convalidación ${ }^{29}$, así como su tramitación como proyecto de ley por el procedimiento de urgencia.

El sentido de las enmiendas presentadas, manifiestan, por diferentes razones, un rechazo a la regulación contenida en el Decreto-Ley y hacen presagiar que el contenido último de la Ley, en función de los apoyos con que cuente, tenderá exclusivamente a convertir en Ley las disposiciones del Decreto-Ley, sin innovaciones de mayor relevancia.

\section{II.6. Los límites materiales}

El Tribunal Constitucional, en su sentencia 29/1982, de 31 de mayo, reprodujo los requisitos exigidos en el artículo 86 de la Constitución para dictar Decretos-Leyes, y a tal efecto señaló lo siguiente:

«Tales requisitos, (...) están recogidos en la C.E., configurando tres bloques definidos: (...); b) la limitación en cuanto a la materia sobre la que puede incidir un Decreto-Ley, lo que supone el que en ningún caso pueda afectar al ordenamiento de las instituciones básicas del Estado, a los derechos, deberes y libertades de los ciudadanos regulados en el título I de la C.E...» (FJ 1).

Como acertó a entender alguna doctrina ${ }^{30}$, el Tribunal Constitucional no pretendía en ese momento resolver si la referencia a los derechos y libertades del Título I, lo era a la totalidad del Título o a la Sección Primera de su Capítulo Segundo, sino simplemente esquematizar el contenido del citado artículo.

Poco después la sentencia 111/1983, de 2 de diciembre, despejaba algunas incógnitas, aunque sin resolver totalmente el problema. En este sentido planteó lo siguiente:

29 Publicado en el Boletín Oficial de las Cortes Generales, de 24 de junio de 1996, núm. 29.

30 Vid. SoRIANO, J.E.: «Los Decretos-Leyes en la jurisprudencia constitucional española», op. cit., pp. 460-461. 
«Una interpretación del artículo 86.1 que lleve en este punto a una restricción de lo que dice su letra, para reducir el ámbito de la limitación de modo que se hagan coincidir las menciones referentes a los derechos y libertades con la materia reservada a la Ley Orgánica, tal como define el artículo 81.1, con trascendencia también para la legislación delegada, aunque implica un esfuerzo hermenéutico que no deja de contar con algunos apoyos, no es conciliable con una interpretación vinculada a unos cánones atentos no sólo al propio sentido literal del precepto, sino, además, a un análisis comparativo con los otros artículos (los arts. 81 y 82) y a lo expuesto en nuestra sentencia de 4 de febrero de 1983 (...) en la que, a propósito del artículo 31 de la CE, situado en la misma sección que el artículo 33 ahora invocado, el criterio adoptado no fue el de la coextensión de los artículos 81.1 y 86.1 de la CE» (FJ 8).

El Tribunal Constitucional, lo mismo que rechaza una restricción del ámbito de limitación material del Decreto-Ley, descarta una interpretación que suponga la total neutralización del Decreto-Ley. Así establece en el mismo Fundamento Jurídico lo siguiente:

...«la tesis partidaria de una expansión de la limitación contenida en el 86.1 de la CE se sustenta en una idea tan restrictiva de la limitación contenida del Decreto-Ley que lleva en su seno el vaciamiento de la figura y la hace inservible para regular con mayor o menor incidencia cualquier aspecto concerniente a las materias incluidas en el Título I de la Constitución sin más base interpretativa que el otorgamiento al verbo "afectar" de un contenido literal amplísimo; como con tan exigua base se conduce a la inutilidad absoluta del Decreto-Ley, pues es difícil imaginar alguno cuyo contenido no afectase a algún derecho comprendido en el título I, es claro que tal interpretación, fácilmente reducible ad absurdum, tampoco puede ser aceptada, ni la aceptó el Tribunal en su sentencia de 4 de febrero de 1983...» (FJ 8).

El Tribunal adopta una posición intermedia que no soluciona, como antes se decía, el problema de interpretación existente. Descarta las posiciones extremas, eso sí, pero deja sin establecer los criterios fijos que sirvan para determinar el ámbito de los derechos, deberes y libertades de los ciudadanos prohibido al Decreto-Ley. O al menos los que fija son orientaciones que siempre habrá que entender adaptables a cada supuesto que fiscalice el Alto Tribunal. En este sentido, continúa señalando lo siguiente:

...«la cláusula restrictiva del art. 86.1 de la C.E. ("no podrán afectar"...) debe ser entendida de modo tal que ni reduzca a la nada el Decreto-Ley, (...), ni permita que por Decreto-Ley se regule el régimen general de los derechos, deberes y libertades del Título I, ni dé pie para que por Decreto-Ley se vaya en contra del contenido o elementos esenciales de 
alguno de tales derechos. Esta vía interpretativa exige también que se tenga muy en cuenta la configuración constitucional del derecho afectado en cada caso e incluso su colocación en el texto constitucional dentro de las diversas secciones y capítulos de su Título I, dotados de mayor o menor rigor protector a tenor del art. 53 de la C.E. En el caso que nos ocupa, el derecho de propiedad, incluida en la Sección Segunda del Capítulo 2. ${ }^{\circ}$ del Título I, aparece regulado en el art. 33, donde se contiene una doble garantía de tal derecho, ya que se reconoce desde la vertiente institucional y desde la vertiente individual, esto es, como un derecho subjetivo, debilitado;...».

Por tanto, para finalizar, de acuerdo con esta doctrina jurisprudencial, que ha sido reiterada, entre otras, en la sentencia 3/1988, de 21 de enero, FJ 7 y 8, es preciso cotejar tres parámetros:

1. ${ }^{\circ}$ La configuración constitucional del derecho afectado, a fin de determinar el grado de protección que la Constitución dispensa.

2. ${ }^{\circ} \mathrm{Si}$ se produce mediante Decreto-Ley una regulación general del régimen general de alguno de los derechos, deberes y libertades contenidos en el Título I.

3. ${ }^{\circ} \mathrm{Si}$ se produce una restricción de alguno de los elementos fundamentales o significativos que componen de esos derechos.

En el caso que nos ocupa, no se produce la incidencia de ninguno de los requisitos o criterios fijados por el Tribunal Constitucional, por lo que cabe simplemente concluir que el analizado Decreto-Ley no desborda los límites materiales planteados por el artículo 86.1 de la Constitución. 


\section{Addenda}

REAL DECRETO-LEY 5/1996, 7 junio. Medidas liberalizadoras en materia de suelo y de Colegios Profesionales (BOE 8 junio 1996; C.E., BOE 18 junio 1996).

\section{EXPOSICION DE MOTIVOS}

Dada la situación del mercado de suelo y la vivienda, se hace necesaria la aprobación de unas primeras medidas que ayudarán a incrementar la oferta de suelo con la finalidad de abaratar el suelo disponible. Las modificaciones propuestas de la legislación urbanística están también orientadas a simplificar los procedimientos y a acortar los plazos vigentes. Se conseguirá así, avanzar en el logro del objetivo público de garantizar con mayor facilidad el acceso a la vivienda y a reducir la enorme discrecionalidad ahora existente.

Así, de acuerdo con el artículo 1, los Planes Generales de Ordenación Urbanística cuya tramitación comience tras la aprobación de este Real Decreto-Ley contendrán una sola clasificación de suelo urbanizable. En el artículo 2, se modifica la cesión de suelo a los ayuntamientos situándola en el 10 por 100. El artículo 3 reduce los plazos de aprobación del planeamiento por los ayuntamientos. El artículo 4, modifica la ley de Bases de Régimen Local facilitando las aprobaciones de los instrumentos de planeamiento y de gestión urbanística. Finalmente, la disposición transitoria establece un procedimiento más sencillo para promover el suelo que el planeamiento vigente o en tramitación clasifique como urbanizable no programado.

En lo que respecta a Colegios Profesionales, se modifican determinados aspectos de la regulación de la actividad de los profesionales que limitan la competencia, introduciendo rigideces difícilmente justificables en una economía desarrollada. En primer lugar, con carácter general, se reconoce la sujeción del ejercicio de las profesiones colegiadas al régimen de libre competencia. En segundo lugar, se establece que el indispensable requisito de colegiación deberá únicamente realizarse en el colegio territorial correspondiente al domicilio del profesional. Finalmente, se elimina la potestad de los Colegios Profesionales para fijar honorarios mínimos, si bien podrán establecer baremos de honorarios orientativos. El Gobierno de la Nación ha sido consciente, desde su toma de posesión, de la necesidad de implementar medidas en la dirección referida con carácter urgente, a fin de aprovechar los efectos sobre la capacidad de crecimiento de la economía española y eliminar los innumerables perjuicios generados por ésta sobre regulación de la economía. Todo lo cual justifica plenamente el empleo de la técnica normativa del Real Decreto-Ley autorizada por el artículo 86 de la Constitución.

En su virtud, a propuesta del Vicepresidente Segundo del Gobierno y Ministro de Economía y Hacienda y de los Ministros de Fomento y Administraciones Públicas previa deliberación del Consejo de Ministros en su reunión del día 7 de junio, en uso de la autorización concedida en el artículo 86 de la Constitución. 


\title{
DISPONGO:
}

\author{
Capítulo primero
}

Suelo

Artículo 1. Supresión de la distinción entre suelo urbanizable programado y suelo urbanizable no programado. Uno. Queda suprimida la distinción entre suelo urbanizable programado y no programado establecida en el Real Decreto-Legislativo 1/1992, de 26 de junio, refundiéndose ambas clases de suelo, denominándose suelo urbanizable.

Dos. Constituirán el suelo urbanizable los terrenos a los que el planeamiento general declare adecuados para ser urbanizados.

Tres. Para el desarrollo urbanístico del suelo urbanizable serán de aplicación las disposiciones contenidas en el Real Decreto-Legislativo 1/1992 para suelo urbanizable programado.

Art. 2. Aprovechamiento y cesión de suelo a los Ayuntamientos. Uno. En suelo urbano el aprovechamiento urbanístico del titular de un terreno no incluido en una unidad de ejecución, será el que resulte de aplicar el aprovechamiento tipo del área de reparto en el que se encuentre o, en su defecto, de la aplicación directa de las ordenanzas o normas urbanísticas de la parcela.

Dos. El aprovechamiento urbanístico que corresponde al titular de un terreno en suelo urbano incluido en una unidad de ejecución y en el suelo urbanizable, será el que resulte de aplicar a su terreno el 90 por 100 del aprovechamiento tipo se tendrá en cuenta el aprovechamiento medio de la unidad de ejecución o del correspondiente sector en que se halle.

Tres. Las obras de rehabilitación y la sustitución de la edificación sin aumento del volumen construido, aun en los casos de hallarse en el ámbito de una unidad de ejecución, no dará lugar a cesiones de aprovechamiento tipo a la corporación.

Art. 3. Reducción de plazos. Con carácter supletorio, y siempre que no se disponga de manera diferente en la legislación urbanística, los plazos de tramitación serán los siguientes:

Uno. El período de información pública al que se hace referencia en los artículos 114.1 y 116 .a) no superará los dos meses.

Dos. En el segundo párrafo del artículo 116.a) la expresión: (...) en los supuestos de planes de iniciativa particular, será de tres meses desde (...); se sustituye por (...) En los supuestos de planes de iniciativa particular, será de dos meses desde (...).

Tres. En el segundo párrafo del artículo 116.a), la expresión: (...) no podrá exceder de un año desde (...); se sustituye por: (...) no podrá exceder de seis meses desde (...).

Cuatro. En el artículo 117.2, la expresión: (...) los Ayuntamientos competentes en el plazo de tres meses (...); se sustituye por (...) los Ayuntamientos competentes en el plazo de dos meses.

Cinco. En el artículo 119.3, la expresión: (...) de detalle, será de tres meses desde (...), se sustituye por: (...) de detalle, será de dos meses desde (...).

Art. 4. Modificación de la Ley 7/1985, de 2 de abril, de Bases del Régimen Local. Uno. Se sustituye el párrafo m) del artículo 21.1 por el siguiente apartado: 
«m) las aprobaciones de los instrumentos de planeamiento de desarrollo del planeamiento general y de gestión urbanística no expresamente atribuidas al Pleno, así como la de los Proyectos de Urbanización.»

Dos. En el artículo 21.1, el párrafo m) en su anterior redacción pasa a ser el párrafo $\mathrm{n}$ ).

Tres. Se modifica el contenido del párrafo c) del artículo 22.2, queda redactado de la siguiente forma:

«c) la aprobación inicial del planeamiento general y la aprobación que ponga fin a la tramitación municipal de los Planes y demás instrumentos de ordenación y gestión previstos en la legislación urbanística.»

Cuatro. Se modifica el contenido del párrafo i) del artículo 47.3, que queda redactado de la siguiente forma:

«i) la aprobación inicial del planeamiento general y la aprobación que ponga fin a la tramitación municipal de los Planes e instrumentos de ordenación previstos en la legislación urbanística.»

\section{DISPOSICION TRANSITORIA}

Urbanismo y suelo. A los procedimientos ya iniciados antes de la entrada en vigor del presente Real Decreto-Ley no les será de aplicación lo dispuesto en los artículos 1,3 y 4 del mismo, rigiéndose por la normativa anterior.

El suelo clasificado como urbanizable no programado en el planeamiento como urbanizable no programado en el planeamiento vigente o en tramitación a la entrada en vigor del presente Real Decreto-Ley, mantendrá el régimen jurídico previsto en la normativa urbanística anterior. No obstante, podrán promoverse y ejecutarse directamente Programas de Actuación Urbanística sin necesidad de concurso, bien por iniciativa pública o por iniciativa privada mediante cualquiera de los sistemas de actuación previstos en la legislación urbanísitca.

\section{DISPOSICION DEROGATORIA}

Quedan derogadas las normas legales o disposiciones administrativas que se opongan a lo previsto en el presente Real Decreto-Ley.

\section{DISPOSICIONES FINALES}

Primera. Al amparo de los artículos 149.1.1..$^{\mathrm{a}}$ 8. $.^{\mathrm{a}}, 13 .^{\mathrm{a}}, 18 .^{\mathrm{a}}$ y $23 .^{\mathrm{a}}$ de la Constitución, se declara el carácter de legislación básica del artículo 2 de este Real Decreto-Ley.

Segunda. Al amparo de los artículos 149.1.1. ${ }^{\mathrm{a}}$ y 149.1.18. ${ }^{\mathrm{a}}$ de la Constitución tienen carácter de legislación básica los artículos 2.1, 2.4, 3.2, 3.3 y 5.ñ de la Ley 2/1974, de 13 de febrero, reguladora de los Colegios Profesionales.

Tercera. El presente Real Decreto-Ley entrará en vigor al día siguiente de su publicación en el Boletín Oficial del Estado. 